\title{
De mãos dadas com a emoção. Uma resenha de A paixão segundo Antonio Gramsci
}

Maria Julia de Paiva ${ }^{1}$

COUTINHO, Eduardo Granja. A paixão segundo Antonio Gramsci. 1 ed. Rio de Janeiro: Editora Mórula, 2020. 123p.

Artigo recebido: março de 2021

Artigo aprovado: maio de 2021

Em tempos tão duros e secos próximos à barbárie nada mais estimulante e afetivo que poder refletir sobre a paixão, em especial na perspectiva do filósofo italiano Antonio Gramsci, dono de uma sensibilidade ímpar, que conseguia perceber o que de potente havia entre uma utopia fria e o raciocínio doutrinário, uma emoção que foi capaz de despertar no povo disperso, uma vontade coletiva.

O princípio da frieza humana, recuperado por Facci e Galuch (2019), originário da lei da equivalência que aparece em Marx e que foi visto por ele a partir das forças produtivas desenvolvidas no capitalismo, segue atual e faz morada na sociedade contemporânea fazendo com que literaturas como esta, de Eduardo Granja Coutinho, nos embale e nos lembre a importância da presença do afeto em tudo que nos afeta.

A paixão segundo Antonio Gramsci versa em seus cinco ensaios sobre a força da teoria revolucionária contida no pensamento de Gramsci, as influências recebidas por ele, assim como a relação entre paixão, mito, vontade coletiva e hegemonia. Disserta sobre o conceito de mito e a capacidade de representação coletiva que 
este encerra organizando a vontade política. De maneira suave e sedutora Eduardo Granja Coutinho discorre sobre o diálogo do intelectual sardo com outros pensadores da tradição marxista, despertando o interesse dos já conhecedores da obra de Gramsci como também dos que ainda buscam conhecer, facilitando a compreensão do processo de superação da concepção de alguns conceitos e categorias pelo qual passou Gramsci.

Coutinho descortina como foi possível Gramsci, por meio de alguns pensadores recuperados por ele na obra, como Maquiavel, Sorel, Labriola, Lenin, Mariátegui, Reich, cada um em uma perspectiva singular que os individualiza, mas que não os separa, encontrar o fio de ligação com a filosofia da práxis, que sob a influência de Antonio Labriola e a revalorização da teoria de Marx, passa a ocupar lugar de categoria central no marxismo (FROSINI, 2011). Labriola percebe que a partir do conhecimento histórico a ação política pode ser pensada coerentemente e prevista, o que provoca em Gramsci a possibilidade de recuperação da noção de práxis.

No primeiro ensaio, "Gramsci e Sorel: a tradução realista do conceito de mito", nos é proposta uma reflexão sobre o conceito de mito e sobre o uso da estratégia de manipulação das emoções em busca de afastar o povo dos processos decisórios, ação já identificada por Maquiavel e ponto relevante no pensamento de Gramsci que vê o mito como o "moderno príncipe" que, como partido, é capaz de expressar uma "vontade coletiva nacional-popular". Coutinho observa que a categoria mito em Gramsci aparece como uma "tradução realista" do conceito pensado por Georges Sorel. É nessa perspectiva do mito que Coutinho se debruça para enfatizar que, não se pode negar a "dimensão estética e passional da política" e que por meio do conceito de mito também podemos acender a chama da vontade popular para a realização de projetos contra-hegemônicos.

O autor evidencia o caráter contraditório do pensamento de Sorel que, ao mesmo tempo em que acredita na capacidade revolucioná- 
ria do proletariado, demonstra dificuldade de perceber que a luta de classes está vinculada ao econômico e social. Seu pensamento nega a filosofia da práxis e é considerado por Lukács "um romântico capitalista”. Contudo, Gramsci utiliza a expressão "espírito de cisão" de Sorel elegendo a dimensão revolucionária contida no conceito no momento em que as classes subalternas adquirem "consciência da própria personalidade histórica". Coutinho salienta como, diversamente de Sorel, Maquiavel privilegia o estudo do passado como possibilidade de previsão de acontecimentos no presente. Gramsci o vê como um "homem de partido", "um político em ato" que se preocupa com o "dever ser" e considera que o "Príncipe" faz despertar emoções e paixões.

Coutinho aborda no segundo ensaio, "Gramsci, herdeiro de Lenin: o problema da relação entre teoria e paixão", a relação entre Gramsci e Lenin, e como Gramsci evolui seu entendimento a respeito da concepção de espontaneidade e voluntarismo percebendo o valor dos processos históricos objetivos tão fundamentais para uma consciência histórica. Gramsci percebe, fundamentado no processo da Revolução Russa, como é possível despertar a paixão nas massas do mundo inteiro, movimentando a consciência proletária e sua organização a partir de uma concepção materialista e dialética da história.

O autor menciona quando Cramsci, na liderança nos Conselhos de Fábrica no movimento de abril de 1920, com aproximadamente 500 mil trabalhadores em greve, sem o apoio partidário e da Central Sindical que resultou infrutífera, como uma experiência propulsora e facilitadora para que o jovem revolucionário italiano percebesse a necessidade da criação de um partido que fosse capaz de construir uma unidade entre todos os movimentos, dando origem ao Partido Comunista Italiana $(\mathrm{PCl})$ em 1921.

Já no terceiro ensaio inédito, "Mito e tradição em Mariátegui", Coutinho escolhe, com muita sensibilidade e emoção, nos trazer o jornalista sociólogo latino americano José Carlos Mariátegui, (conhecido na sua aldeia como Amauta), e sua reflexão diferenciada sobre ideologia. Sua 
visão sobre o valor da paixão na política o aproxima de Gramsci, não por acaso, já que Mariátegui foi para a Itália em 1920 permanecendo até 1923, quando se torna marxista. Mariátegui recebeu influência não só do semanário italiano L'Ordine Nuovo, onde Gramsci escrevia, como de outros pensadores. Interpretou a sua aldeia no Peru povoada por índios utilizando "recursos heurísticos do marxismo".

Assim como aconteceu com Gramsci, Coutinho aborda como Mariátegui foi marcado pelo conceito de mito de Sorel e que depositou um misticismo no materialismo socialista. Para Mariátegui a civilização burguesa necessitava de um mito. Na perspectiva de Gramsci, a burguesia liberal italiana do século XIX estava em crise e o Estado liberal não tinha mais condições de satisfazer os interesses das classes dominantes, por esse motivo, era visivel a crise de hegemonia sendo a Primeira Guerra Mundial o resultado concreto desta crise.

No quarto ensaio fecunda o que vai além das palavras, o intrínseco que bate no coração não carnal, o que vem na poesia e na relação entre paixão e ideologia. Em "As cinzas de Gramsci: Pasolini e a crise da vontade revolucionária" o autor nos surpreende com o poema de Pasolini de complexo entendimento, e retrato da realidade política da época, sem com isso comprometer o "prazer da estética" de quem o lê, como é lembrado por Coutinho. O autor, no decorrer do ensaio e com muita propriedade, vai tecendo a teia de ligação entre os versos do poeta, a história e a trajetória revolucionária de Gramsci.

Neste ensaio, Coutinho narra como Pasolini, um escritor ativo e cineasta presente na luta dos trabalhadores, tornou-se um "pessimista e desesperançado" em função dos acontecimentos na década de 1950, após a Segunda Guerra Mundial, que esfacelou o que havia de revolucionário na sociedade européia provocando um desencantamento com as possibilidades trazidas pela Revolução Russa e o stalinismo. Tantos outros fatos, tais como: a perda de liderança do Partido Comunista Italiano, a Guerra Fria e a evidência de diversos tipos de intolerâncias, foram responsáveis 
pelas reflexões contidas no poema. O poeta negou a fé revolucionária dos partidos comunistas embora nunca tenha abandonado o marxismo. Interpretou a realidade daquele período como "pausa sussurrante em que a vida cala".

No quinto e último ensaio, "Gramsci, Reich e o fascismo", também inédito, Coutinho privilegia o leitor com a brilhante aproximação entre o psicanalista Wilheim Reich e o intelectual Antonio Gramsci. Reich, em 1920 iniciou sua participação na Sociedade Vienense de Psicanálise e em 1922 tornou-se o primeiro assistente de Sigmund Freud. No entanto, posteriormente o psicanalista questionou as teorias culturais de Freud e passou a professar o conceito de "causação social das neuroses" (REICH, 1976). Nesse ensaio, Coutinho inicia seu texto com um questionamento ainda muito atual e que ocupou os dois revolucionários em suas pesquisas: "O que faz com que as massas se submetam voluntariamente a regimes autoritários?".

O autor discorre sobre os caminhos percorridos pelos dois pesquisadores, as perspectivas de cada um, as teorias utilizadas, os questionamentos gerados pelo êxito do fascismo, os conceitos desenvolvidos e alguns pontos em comum como a influência do pensamento de Marx e Lenin, a participação nos partidos comunistas italiano e alemão e a não dissociação da emoção e da razão na política. Fica claro, na leitura do texto que, embora os dois pensadores se distingam nas buscas teóricas, ambos têm a mesma preocupação e estavam atentos “à dimensão emocional da política”.

Ao longo do livro nos cinco ensaios, Coutinho estabelece uma relação poética entre paixão, ideologia, política, razão, emoção, submissão, esperança, otimismo, pessimismo e tantos sentimentos presentes como se fossem versos contados da história dos diversos protagonistas revolucionários presentes nos ensaios, companheiros na vida ou no pensamento de Gramsci e que percorreram caminhos, às vezes um pouco mais distintos outras vezes bem próximos, mas que levam ao lugar da luta onde mora a vontade revolucionária. 
Ler esse livro é um afago na esperança. É como se lê um romance com início, meio, mas sem fim, porque o romance está inacabado e, ainda, promete muitas emoções como as contidas na vida revolucionária desses personagens que compuseram com Gramsci a história de hoje, e nos oportuniza escrever a história de amanhã.

\section{Referências}

FACCI, Douglas Tadeu da Silva; GALUCH, Maria Therezinha Bellanda. Frieza burguesa: apontamentos para uma teoria da formação da subjetividade moderna. Acta Scientiarum. Human and Social Sciences, v. 41, n. 1, 2019.

FROSINI, Fabio. Minicurso Filosofia da praxis de Antonio Gramsci Marxismo/ Filosofia da práxis. Núcleo de Estudos e Pesquisas em Filosofia, Política e Educação (NuFiPE), Universidade Federal Fluminense, Niterói-RJ, 25-26 de agosto de 2011.

REICH, William. A revolução sexual. Trad. Ary Blaustein. 3 ed. Rio de Janeiro: Zahar Editores, 1976.

\section{Nota}

1 Doutoranda em Serviço Social pela Pontifícia Universidade Católica do Rio de Janeiro (PUC-Rio). Mestre em Ciências da área de Saúde Pública pela Escola Nacional de Saúde Pública (ENSP) da Fundação Oswaldo Cruz (FIOCRUZ-RJ). Psicóloga da Equipe de Referência Infanto-juvenil para ações de Atenção ao uso de Álcool e outras Drogas (ERIJAD) no município de Niterói/RJ. Pesquisadora no Núcleo de Estudos e Pesquisas em Filosofia, Política e Educação (NuFiPE/ UFF) e no Grupo de Estudos e Pesquisas Trabalho, Políticas Públicas e Serviço Social (Trappus/PUC-Rio). Brasil. ORCID: https://orcid.org/0000-0002-54595017 E-mail: julia-paiva@hotmail.com 